\title{
BMJ Open Prevalence and determinants of potentially inappropriate medication use in Hong Kong older patients: a cross-sectional study
}

\author{
Huanyu Zhang (D) , Eliza LY Wong, Samuel YS Wong, Patsy YK Chau, \\ Benjamin HK Yip, Roger YN Chung (D) , Eric KP Lee, Francisco TT Lai (D) , \\ Eng-Kiong Yeoh
}

To cite: Zhang H, Wong ELY, Wong SYS, et al. Prevalence and determinants of potentially inappropriate medication use in Hong Kong older patients: a cross-sectional study. BMJ Open 2021;11:e051527. doi:10.1136/ bmjopen-2021-051527

- Prepublication history and additional online supplemental material for this paper are available online. To view these files, please visit the journal online (http://dx.doi.org/10. 1136/bmjopen-2021-051527).

Received 24 March 2021 Accepted 05 July 2021

Check for updates

(c) Author(s) (or their employer(s)) 2021. Re-use permitted under CC BY-NC. No commercial re-use. See rights and permissions. Published by BMJ.

The Jockey Club School of Public Health and Primary Care, The Chinese University of Hong Kong, Sha Tin, New Territories, Hong Kong

Correspondence to Professor Eliza LY Wong; lywong@cuhk.edu.hk

\section{ABSTRACT}

Objectives To assess the prevalence of potentially inappropriate medication (PIM) use in Hong Kong older patients visiting general outpatient clinics (GOPCs) between 2006 and 2014 and to identify factors associated with PIM use among older adults visiting GOPCs in 2014

Design Cross-sectional study.

Setting GOPC.

Participants Two study samples were constructed including a total of 844910 patients aged 65 and above from 2006 to 2014 and a cohort of 489301 older patients in 2014.

Measurements Two subsets of the 2015 American Geriatrics Society Beers criteria-PIMs independent of diagnosis and PIMs due to drug-disease interactionswere used to estimate the prevalence of PIM use over 12 months. PIMs that were not included in the Hospital Authority drug formulary or with any specific restriction or exception in terms of indication, dose or therapy duration were excluded. Characteristics of PIM users and non-PIM users visiting GOPCs in 2014 were compared. Independent associations between patient variables and PIM use were assessed by stepwise multivariable logistic regression analysis.

Results The 12-month period prevalence of PIM use decreased from $55.56 \%$ (95\% Cl $55.39 \%$ to $55.72 \%$ ) in 2006 to $47.51 \%$ (95\% Cl $47.37 \%$ to $47.65 \%$ ) in 2014 . In the multivariable regression analysis, the strongest factor associated with PIM use was the number of different drugs prescribed (adjusted OR, AOR 23.01, 95\% Cl 22.36 to 23.67). Being female (AOR $0.89,95 \% \mathrm{Cl} 0.85$ to 0.87 for males vs females) and having a greater number of GOPC visits (AOR 1.83, 95\% $\mathrm{Cl} 1.78$ to 1.88 ) as well as more than six diagnoses (AOR 1.43, 95\% $\mathrm{Cl} 1.36$ to 1.52 ) were associated with PIM use.

Conclusions The overall prevalence of PIM use in older adults visiting GOPCs decreased from 2006 to 2014 in Hong Kong although the prevalence of PIM use was still high in 2014. Patients with female gender, a larger number of medications prescribed, more frequent visits to GOPCs, and more than six diagnoses were at higher risk for PIM use.

\section{Strengths and limitations of this study}

- This is the first territory-wide study assessing the prevalence of potentially inappropriate medication (PIM) use in older adults over a 9-year period from 2006 to 2014 in Hong Kong.

- Since this study was retrospective using an administrative database, a limited number of PIM statements from the 2015 American Geriatrics Society (AGS) Beers criteria were employed, resulting in the underestimation of the prevalence of PIM use in older adults in Hong Kong.

- Although the PIM list extracted from the 2015 AGS Beers criteria can be used to assess the appropriateness of prescribing at the population level in Hong Kong, it may overestimate the prevalence of PIM use in older adults for the benefits of PIMs may outweigh risks at the individual level.

\section{BACKGROUND}

Potentially inappropriate medication (PIM) use occurs when patients are prescribed drugs the associated risks of which outweigh potential benefits, ${ }^{1}$ especially when effective alternatives are available. PIM use can cause adverse drug events, which contribute to increased morbidity and mortality as well as higher healthcare expenditures. ${ }^{2}$ Older adults are particularly at risk for PIM use because of the high likelihood of comorbid diseases, necessitating the prescription of multiple medications. ${ }^{3}$ In Hong Kong, people aged 65 years or older (hereafter referred to as 'older adults'), accounted for $15.9 \%$ of the total population in mid-2016, and this percentage is estimated to reach $33.7 \%$ by $2066 .{ }^{4}$ To present a wider perspective, in 2019, the proportions of older adults in the populations of Europe and North America were estimated to be $18.8 \%$ and $16.4 \%$, respectively. ${ }^{5}$ Therefore, the detection of 
PIM use among older adults worldwide, including Hong Kong, has become an important public health concern.

PIM use among older adults can be assessed by explicit criterion-based measures or implicit judgement-based measures. ${ }^{6}$ Explicit criteria are usually drug or disease oriented that are developed from literature review, expert opinions and consensus techniques. ${ }^{7}$ They can be applied to large samples of people to assess the prevalence of PIM use from a macro level. On the other hand, the application of implicit criteria in assessing the appropriateness of prescribing require a clinician's judgement based on an individual's clinical information. Since it is time consuming and costly to use implicit criteria to evaluate the appropriateness of prescribing, ${ }^{8}$ explicit criteria are more favoured to assess the prevalence of PIM use in population-based studies.

The first set of explicit criteria assessing the appropriateness of prescribing was the Beers criteria, created in $1991^{9}$ in the USA and updated in $1997^{10}$ and $2003{ }^{11}$ However, as these early versions incurred criticism, ${ }^{12}{ }^{13}$ the American Geriatrics Society (AGS) expert panel made a major revision to the 2012 Beers criteria by incorporating new evidence of safety and efficacy of drug use. ${ }^{14}$ The contents of the 2012 AGS Beers criteria mainly included three categories: drugs that should be generally avoided, drugs that should be avoided due to specific diseases or syndromes, and drugs that should be used with caution in older adults. ${ }^{14}$ Subsequently, two new categories-drugdrug interactions and drugs to avoid based on kidney function-were added to the 2015 AGS Beers criteria. ${ }^{15}$ These five categories remain in the 2019 version, which is the most up to date. ${ }^{16}$ The Beers criteria were widely used to assess the prevalence of PIM use in a variety of settings across different countries beyond the USA ${ }^{17-20}$ Hence, it is convenient to make an international comparison of the prevalence of PIM use by applying the Beers criteria in the local context.

In Hong Kong, the Hospital Authority (HA) is responsible for the management of all the public health services, including 43 public hospitals, 49 specialist outpatient clinics and 73 general outpatient clinics (GOPCs) across seven geographical clusters. ${ }^{21}$ Over $90 \%$ of inpatient services in Hong Kong are provided by public hospitals, whereas $70 \%$ of outpatient consultations are provided by private sectors. ${ }^{22}$ Patients who cannot afford outpatient services in private sectors can use public services instead. Older adults are major consumers of public health services in Hong Kong; this population accounted for around half of all patient days at public hospitals and $38 \%$ of the GOPC visits at public clinics. ${ }^{22}$ Public health services including drug fees are highly subsidised by the Hong Kong government. Therefore, quantifying and reducing the burden of PIM use is likely to aid in the reduction of healthcare costs. Although there have been studies in Hong Kong using the Beers criteria to evaluate the prevalence of PIM use in older adults, ${ }^{23} 24$ these have generally either been conducted at a single hospital or employed small sample sizes. So far, there has been no territory-wide study to assess PIM use in Hong Kong. Hence, the aim of this study was to describe the prevalence of PIM use in older adults using territory-wide data over a 9-year period from all public GOPCs and to identify patient characteristics associated with PIM use in Hong Kong, China.

\section{METHODS}

\section{Data source}

This study was a cross-sectional study using the HA database from 2006 to 2014. The primary care clinicians collected patients' electronic health records with the HA computer system. Since the HA computer system covers all the patients who attend GOPCs in Hong Kong, the data extracted from the HA database are highly reliable; there were no missing data in the datasets. The proportion of the ageing population attending GOPCs in Hong Kong ranged from $41.6 \%$ to $46.2 \%$ from 2006 to 2014, with an increasing trend over time. ${ }^{4}$ All the patient records in the HA database were anonymised and deidentified. A unique identity code was allocated to each patient so as to link them up across different datasets. Two different study cohorts were constructed to evaluate the proposed objectives.

A cohort of older adults visiting GOPCs from 1 January 2006 to 31 December 2014 were extracted from the general outpatient dataset to estimate the prevalence of PIM use in this study. All the diagnoses of patients visiting GOPCs were coded with International Classification of Primary Care, Second edition (ICPC-2) system. The prescription records of the study population were extracted from the medication datasets, which included drug prescriptions in the primary care setting. The medication datasets provided information on generic names of medications originating from the HA drug formulary, which were lack of details of indication, dose or therapy duration.

To identify patient characteristics associated with PIM use, another cohort was constructed containing patients aged 65 years or older visiting GOPCs from 1 January 2014 to 31 December 2014. Information on the healthcare service utilisation in the previous year (any hospital admission, accident and emergency (A\&E) department visit and GOPC visit) was also extracted from the HA database. Patients who experienced hospital transits were considered as only one hospital admission. Each consultation episode per patient was identified by a unique sequence number. The following patient characteristics were taken into account: gender, age, number of different drugs prescribed, number of diagnoses, number of GOPC visits within the year and any healthcare service utilisation in the previous year. The number of diagnoses and medications per person were calculated based on the number of ICPC-2 codes and generic drug names, respectively. Since the data were retrospective, pre-existing and deidentified, we had no access to any sensitive information on patients, physicians and clinics. 


\section{Operational definition of PIM use}

The 2015 AGS Beers criteria included 5 categories of PIM use. The category of drugs that should be used with caution can be used under specific circumstances, thus it is not the key element of the criteria. ${ }^{15}$ The list of drug-drug interactions is selective and not comprehensive. ${ }^{15}$ The drugs to avoid based on kidney function require laboratory values, which are not included in the HA database. Hence, these three categories of PIM use were not considered in the current study. The operational definition of PIM use for this study included the other two categories of PIMs in the 2015 AGS Beers criteria, namely, PIMs independent of diagnosis and PIMs due to drug-disease interactions. Since some of the defined PIMs are not available in the drug market of Hong Kong, the Beers criteria cannot be applied without going through a process of context modification. Given that the drugs listed in the HA drug formulary are frequently prescribed or dispensed at public clinics, the applicability of the Beers criteria in Hong Kong was examined in the context of the HA drug formulary, ${ }^{25}$ with the exclusion of the Beers drugs that were not covered by the formulary. Also, as the HA database was lack of complete prescribing information, PIMs with any exception or restriction in terms of indication, dose or therapy duration were excluded. Hence, among the 40 statements under PIMs independent of diagnosis and 12 statements under PIMs due to disease-drug interactions from the 2015 AGS Beers criteria, the final PIM assessment criteria adapted to Hong Kong contained 11 statements under PIMs independent of diagnosis and 12 statements under PIMs due to drug-disease interactions (online supplemental file 1).

\section{Statistical analysis}

A cross-sectional study was conducted to analyse the 12-month period prevalence of PIM use in older adults visiting GOPCs in Hong Kong from 2006 to 2014. The 12-month period prevalence of PIM use was defined as the number of older adults with at least one PIM use during the calendar year divided by the number of older adults visiting GOPCs during the calendar year.

A descriptive analysis was performed on the characteristics of PIM users and non-PIM users in 2014. $\chi^{2}$ tests were used to compare differences between PIM users and non-PIM users. A stepwise multivariable logistic regression analysis was conducted to identify the risk factors associated with having at least one PIM use in older adults visiting GOPCs. The variance inflation factor (VIF) for each independent variable in the reported model was examined to rule out multicollinearity. When we included the variables of healthcare service utilisation in the previous year (any hospital admission, A\&E department visit and GOPC visit) in the regression model, the value of VIF for each of these variables was more than 10 , which indicated a problem of collinearity. Therefore, we decided to exclude the variables of any healthcare service utilisation in the previous year in the reported model. Wald tests were used to evaluate the statistical significance of each independent variable in the model. Adjusted ORs (AORs) were reported with $95 \%$ CIs. A $p<0.05$ was considered statistically significant. R V.3.4.3 software was used for all statistical analyses.

Patient and public involvement

No patient involved.

\section{RESULTS}

The study population included 844910 older adults in the 9-year period from 2006 to 2014 with a mean number of 4.6 $\pm 2.8 \mathrm{GOPC}$ visits per person. The mean age of the sample was $75.3 \pm 7.3$ years $(26.6 \%$ aged $\geq 80)$ and $45.2 \%$ were males. The mean number of diagnoses and different medications prescribed were $4.0 \pm 2.0$ and $9.4 \pm 6.8$, respectively (table 1 ).

Of the 489301 older adults visiting GOPCs during 2014, 47.5\% were prescribed at least one PIM (table 2). Among the patients who were prescribed PIMs, 62.9\% were prescribed one PIM, followed by $27.5 \%$ with two PIMs, $7.5 \%$ with three PIMs and $2.1 \%$ with more than three PIMs prescribed. Significant differences between PIM users and non-PIM users were found in gender, number of different drugs prescribed, number of diagnoses, number of GOPC visits within the year and healthcare service use in the previous year $(p<0.001)$. PIM users made more frequent use of healthcare services in the previous year than non-PIM users in terms of GOPC visits, A\&E visits and hospital admissions $(\mathrm{p}<0.001)$. However, the variable age was not significantly different between the two groups $(\mathrm{p}=0.076)$.

In this study, the 12-month period prevalence of PIM use decreased from $55.56 \%$ (95\% CI $55.39 \%$ to $55.72 \%$ ) in 2006 to $47.51 \%$ (95\% CI $47.37 \%$ to $47.65 \%$ ) in 2014 (figure 1). The prevalence of PIMs independent of diagnosis accounted for the majority of PIM use and exhibited a similar trend to the total prevalence: a decline from $55.05 \%$ (95\% CI $54.89 \%$ to $55.22 \%$ ) in 2006 to $46.79 \%$ (95\% CI $46.65 \%$ to $46.93 \%)$ in 2014 . The prevalence of PIMs due to drug-disease interactions increased slightly from $3.18 \%$ (95\% CI $3.12 \%$ to $3.23 \%$ ) in 2006 to $4.69 \%$ (95\% CI $4.63 \%$ to $4.75 \%)$ in 2014.

The full list of the prevalence of PIM use for individual PIMs and PIMs due to disease-drug interactions is shown in online supplemental file 2 . Table 3 presents the PIMs that were prescribed in over $1 \%$ of the older adults visiting GOPCs in 2014. The most frequently prescribed PIMs independent of diagnosis were chlorpheniramine $(35.40 \%)$, promethazine $(8.73 \%)$, diphenhydramine $(8.44 \%)$ and methyldopa $(4.07 \%)$. The most common PIMs due to drug-disease interactions were medications exacerbating lower urinary tract symptoms or benign prostatic hyperplasia $(3.66 \%)$, followed by medications worsening dementia or cognitive impairment $(1.08 \%)$.

The relationships between patient characteristics and PIM use were identified in the multivariable logistic regression analysis (table 4). The strongest factor associated 


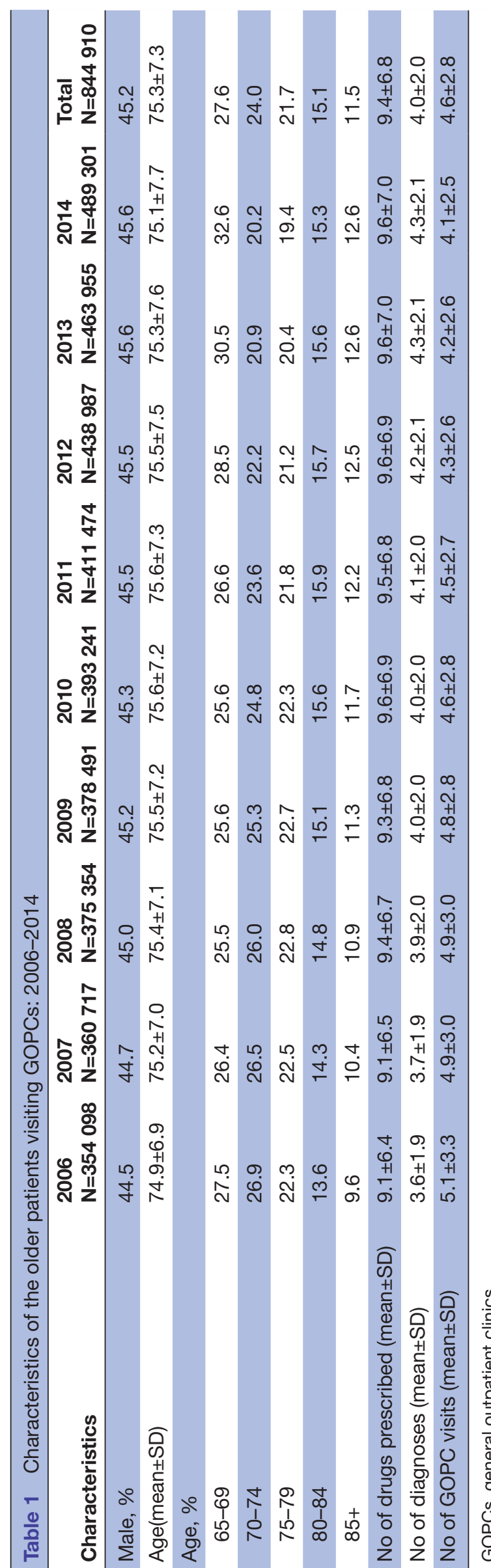

with PIM use was number of different drugs prescribed (AOR 23.01, 95\% CI 22.36 to 23.67 for $>12$ drugs $v s<3$ ). Females were more likely to receive PIMs than males (AOR $0.89,95 \%$ CI 0.85 to 0.87 for males vs females). A greater number of GOPC visits within the year was also associated with a greater risk of PIM use (AOR 1.83, 95\% CI 1.78 to 1.88 for $>5$ visits vs 1 ). Patients with more than six diagnoses were associated with higher rates of PIM use (AOR $1.43,95 \%$ CI 1.36 to 1.52 ). All the variables in the model have a value of VIF far below 5 , which indicated no problem of collinearity. All the independent predictors were proved to be significantly important with a $p$ value less than 0.001 generated by the Wald test.

\section{DISCUSSION}

This study used the major subsets of the 2015 AGS Beers criteria to assess the burden of PIM use at GOPCs in older adults in Hong Kong between 2006 and 2014. The prevalence estimates of PIM use in the current study were generally higher than that previously reported in Hong Kong ranging from $30.3 \%$ to $38.6 \%{ }^{23}{ }^{24}$ A recent systematic review summarised 12 studies conducted in different countries across Europe, North America, South America, Asia, Africa and Oceania that used the 2015 AGS Beers criteria to assess the percentage of PIM use among community patients aged 65 years or above. ${ }^{26}$ The weighted average percentage of patients who were prescribed one or more PIM was $58 \%$ for 593389 community patients, ${ }^{26}$ which was relatively higher than that reported in the current study. However, most of these studies included in the systematic review only employed a small sample size with lack of representativeness. More population-based studies are needed to assess the prevalence of PIM use in older adults using the 2015 AGS Beers criteria. The present study showed a decreasing trend of PIM use in Hong Kong, although a large number of older adults were still exposed to PIMs. The HA continuously widens the scope of the drug formulary to include more costeffective drugs with proven clinical efficacy, which can partly explain the decreasing trend of PIM use in Hong Kong. Given the changing prescribing frequency and the release of new PIM assessing criteria, it is important to have access to updated figures regarding the prevalence of PIM use in older adults. The results indicate that PIM use is prevalent in community-dwelling older adults in Hong Kong and it is necessary to monitor medication use in these patients. The HA computer system should alert prescribers to the high risk of PIM use among vulnerable patients. Since the HA drug formulary is updated quarterly every year, the mechanism of reviewing evidence on the selection of the HA drug formulary should take the frequently prescribed PIMs into account by excluding drugs with an unfavourable benefit/risk ratio to older patients and purchasing therapeutic alternatives.

Several factors may account for the high prevalence of PIM use in older adults visiting GOPCs in Hong Kong. First, the prevalence of multimorbidity has been increasing and 
Table 2 Characteristics of PIM users versus non-PIM users visiting GOPCs in 2014

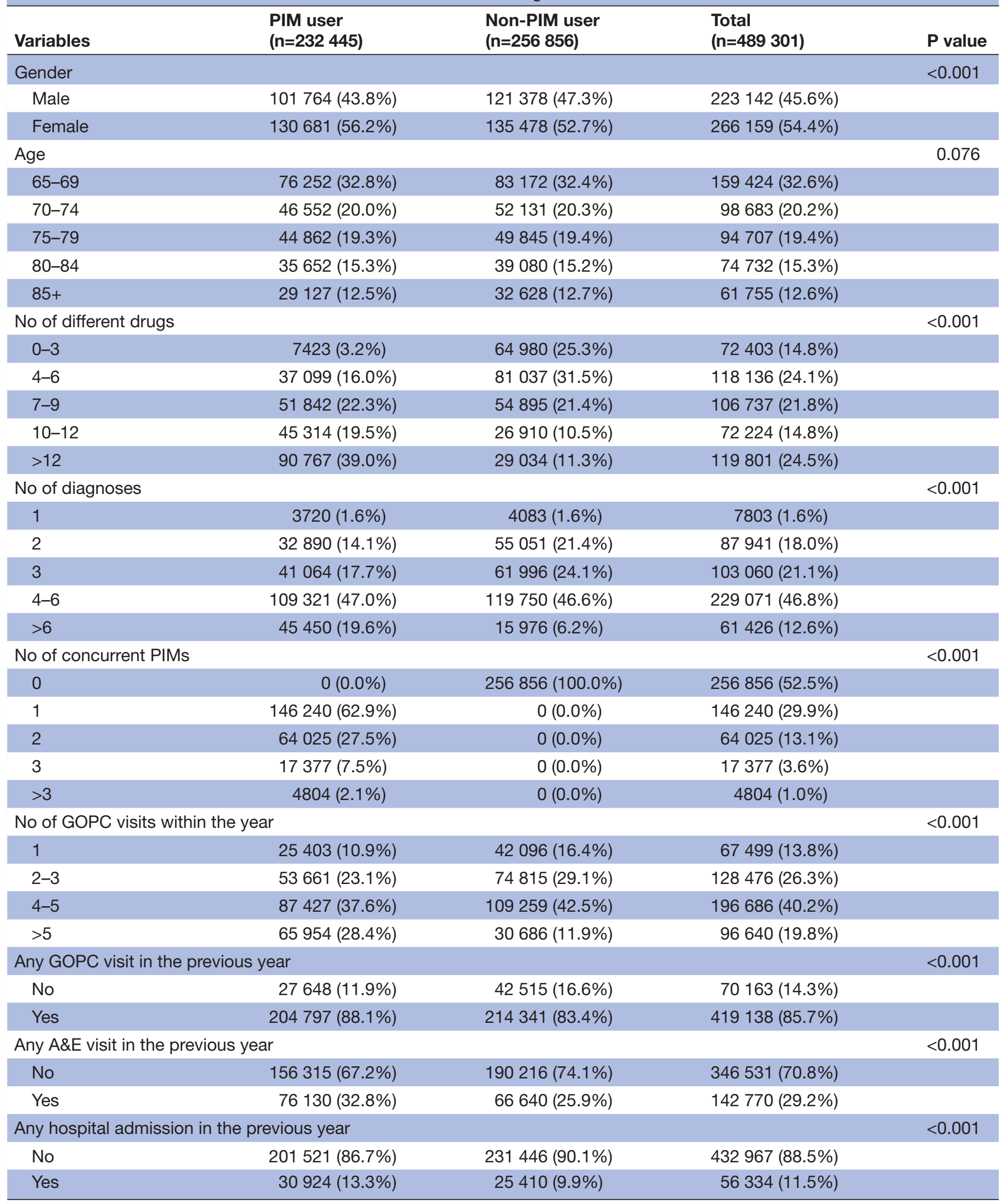

A\&E, accident and emergency; GOPC, general outpatient clinic; PIM, potentially inappropriate medication. 


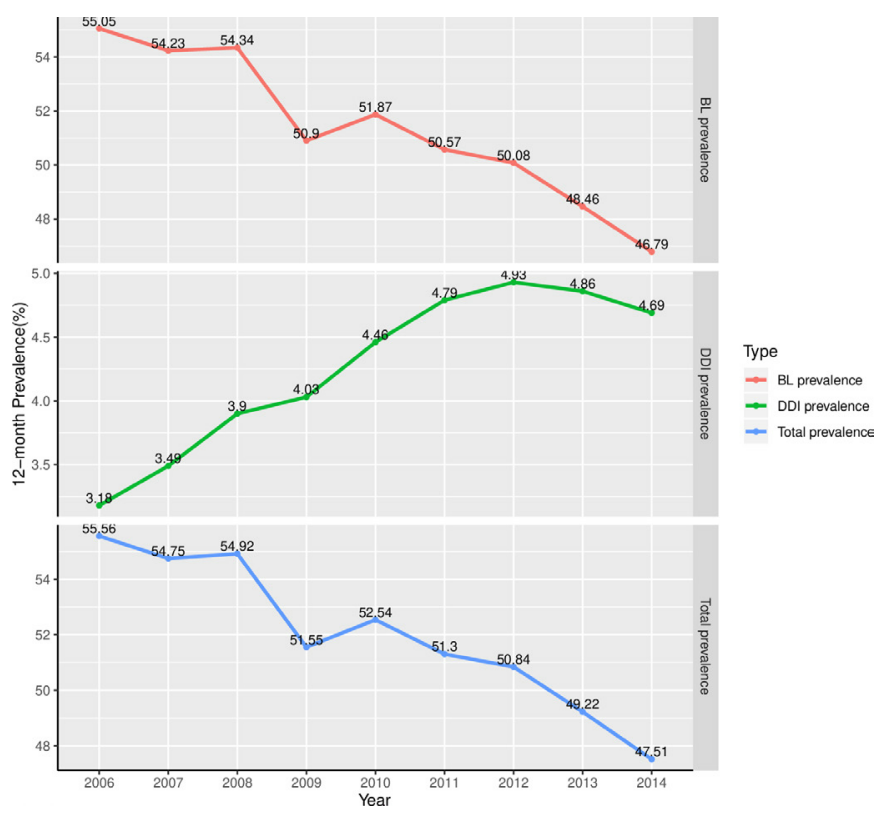

Figure 1 The 12-month prevalence of PIM use in Hong Kong older patients at GOPCs between 2006 and 2014. BL, Beers list (PIMs independent of diagnosis); DDI, drug-disease interaction (PIMs due to drug-disease interactions); GOPC, general outpatient clinic; PIM, potentially inappropriate medication.

patients with chronic conditions often consult multiple doctors in public clinics, which can elevate the risk of PIM exposure ${ }^{27}$ Although the HA established a chronic disease management programme at selected GOPCs to enhance drug use safety in $2009,{ }^{28}$ GOPCs do not conduct regular reviews of a patient's medication list. Second, healthcare financing might contribute to PIM use. The Hong Kong health system is funded by taxation, and GOPC services, including drug expenses, are highly subsidised. ${ }^{29}$ The copayment for GOPC services is HK $\$ 50$ (US\$7.5) per visit without any medication copayment, ${ }^{30}$ compared with an average of HK $\$ 200$ at a private clinic. ${ }^{29}$ Consequently, older adults are more willing to attend public clinics and frequent GOPC visits could increase the risk of PIM exposure. In addition, doctors are not required to have formal training in family medicine to practice at GOPCs in Hong Kong. ${ }^{31}$ Under the circumstances, it is likely that some of the general practitioners at GOPCs may have insufficient knowledge in pharmacotherapy for older adults and lack awareness of the risks of PIM use. Furthermore, the prescribing rate of first-generation antihistamines is relatively high in Hong Kong older patients mainly because clinicians at GOPCS are inclined to prescribe first-generation antihistamines for patients to treat colds. Since the PIM statements with a therapy duration were not included in the current study, the consideration of shortterm prescriptions only also contributed to the detection of frequent use of first-generation antihistamines in older adults. Overall, prescribers in Hong Kong should be more careful on prescribing first-generation antihistamines for older patients since the risks may outweigh benefits. In contrast, the prescribing rates of benzodiazepines or other hypnotics were relatively low in Hong Kong compared with that reported in previous studies conducted in other countries. ${ }^{1}$ This is probably because all the benzodiazepines and other hypnotics are classified

Table 3 The most frequently prescribed PIMs among older adults visiting GOPCs in 2014 according to the 2015 AGS Beers criteria

\begin{tabular}{|c|c|c|}
\hline Medication class & Medication & Prevalence of PIM use, \% \\
\hline \multicolumn{3}{|l|}{ PIMs independent of diagnosis } \\
\hline First-generation antihistamines & Chlorpheniramine & 35.40 \\
\hline First-generation antihistamines & Diphenhydramine & 8.44 \\
\hline Central alpha blockers & Methyldopa & 4.07 \\
\hline Benzodiazepines & Lorazepam & 1.15 \\
\hline NSAIDs & Indomethacin & 1.14 \\
\hline Antidepressants & Amitriptyline & 1.07 \\
\hline First-generation antihistamines & Hydroxyzine & 1.04 \\
\hline Disease/ Syndrome & Medication class/medication & Prevalence of PIM use, $\%$ \\
\hline Dementia or cognitive impairment & $\begin{array}{l}\text { Anticholinergics, benzodiazepines, } \mathrm{H} 2- \\
\text { receptor antagonists (famotidine, ranitidine), } \\
\text { zolpidem, antipsychotics }\end{array}$ & 1.08 \\
\hline
\end{tabular}

AGS, American Geriatrics Society; GOPC, general outpatient clinic; PIM, potentially inappropriate medication. 


\begin{tabular}{|c|c|c|}
\hline \multirow[b]{2}{*}{ Variables } & \multicolumn{2}{|l|}{ OR $(95 \% \mathrm{Cl})$} \\
\hline & Crude & Adjusted \\
\hline \multicolumn{3}{|l|}{ Gender } \\
\hline Female & 1.00 & 1.00 \\
\hline Male & $0.87(0.86 \text { to } 0.88)^{\star \star \star}$ & $0.86(0.85 \text { to } 0.87)^{\star \star \star}$ \\
\hline \multicolumn{3}{|l|}{ Age } \\
\hline $65-69$ & 1.00 & - \\
\hline $70-74$ & $0.97(0.96 \text { to } 0.99)^{\star \star}$ & \\
\hline $75-79$ & $0.98(0.97 \text { to } 1.00)^{*}$ & \\
\hline $80-84$ & 1.00 (0.98 to 1.01$)$ & \\
\hline $85+$ & $0.97(0.96 \text { to } 0.99)^{\star \star}$ & \\
\hline \multicolumn{3}{|c|}{ No of unique drugs } \\
\hline $0-3$ & 1.00 & 1.00 \\
\hline $4-6$ & $4.01(3.90 \text { to } 4.12)^{\star \star \star}$ & $3.96(3.86 \text { to } 4.07)^{\star \star \star}$ \\
\hline $7-9$ & $8.27(8.05 \text { to } 8.49)^{\star \star \star}$ & $7.87(7.65 \text { to } 8.09)^{\star \star \star}$ \\
\hline $10-12$ & $14.74(14.33 \text { to } 15.17)^{\star \star \star}$ & $13.18(12.80 \text { to } 13.57)^{\star \star \star}$ \\
\hline$>12$ & $27.37(26.63 \text { to } 28.13)^{\star \star \star}$ & $23.01(22.36 \text { to } 23.67)^{\star \star \star}$ \\
\hline \multicolumn{3}{|c|}{ No of diagnoses } \\
\hline 1 & 1.00 & 1.00 \\
\hline 2 & $0.66(0.63 \text { to } 0.69)^{\star \star \star}$ & $1.13(1.08 \text { to } 1.20)^{\star \star \star}$ \\
\hline 3 & $0.73(0.69 \text { to } 0.76)^{\star \star \star}$ & 1.02 (0.97 to 1.08$)$ \\
\hline $4-6$ & $1.00(0.96$ to 1.05$)$ & $0.94(0.89 \text { to } 0.99)^{\star}$ \\
\hline$>6$ & $3.12(2.97 \text { to } 3.28)^{\star \star \star}$ & $1.43(1.36 \text { to } 1.52)^{\star \star \star}$ \\
\hline \multicolumn{3}{|c|}{ No of GOPC visits within the year } \\
\hline 1 & 1.00 & 1.00 \\
\hline $2-3$ & $1.19(1.17 \text { to } 1.21)^{\star \star \star}$ & $1.17(1.14 \text { to } 1.19)^{\star \star \star}$ \\
\hline $4-5$ & $1.33(1.30 \text { to } 1.35)^{\star \star \star}$ & $1.16(1.14 \text { to } 1.19)^{\star \star \star}$ \\
\hline$>5$ & $3.56(3.49 \text { to } 3.64)^{\star \star \star}$ & $1.83(1.78 \text { to } 1.88)^{\star \star \star}$ \\
\hline \multicolumn{3}{|c|}{ Any GOPC visit in the previous year } \\
\hline No & 1.00 & - \\
\hline Yes & $1.47(1.45 \text { to } 1.49)^{\star \star \star}$ & \\
\hline \multicolumn{3}{|c|}{ Any A\&E visit in the previous year } \\
\hline No & 1.00 & - \\
\hline Yes & $1.39(1.37 \text { to } 1.41)^{\star \star \star}$ & \\
\hline \multicolumn{3}{|c|}{ Any hospital admission in the previous year } \\
\hline No & 1.00 & - \\
\hline Yes & $1.40(1.37 \text { to } 1.42)^{\star \star \star}$ & \\
\hline
\end{tabular}

${ }^{*} \mathrm{P}<0.05,{ }^{* *} \mathrm{p}<0.01,{ }^{* * *} \mathrm{p}<0.001$

- Not included in the multivariable model.

A\&E, accident and emergency; GOPC, general outpatient clinic; PIM, potentially inappropriate medication.

as dangerous drugs under the Dangerous Drugs Ordinance in Hong Kong. Clinicians would be very careful when prescribing benzodiazepines or other hypnotics to older adults in Hong Kong. The prescription of benzodiazepines or other hypnotics may occur when there is no better alternative or the benefit outweighs its risk.

Previous studies suggested that the prescribing of PIMs was associated with the female gender, advancing age and larger number of drugs prescribed. ${ }^{32}$ The results of the current study were consistent with previous studies in terms of greater risk of PIM use in females and patients who were prescribed more drugs. However, the variable age was not significantly associated with PIM use. Some recent studies have indicated that the risk of receiving PIMs decreases with age. ${ }^{12} 33$ The inconsistent results may depend on the study sample, the PIM criteria applied and the inclusion of diagnoses, making it difficult to make a proper comparison. More evidence is needed to identify the relationship between age and PIM exposure. In the multivariable regression analysis, the number of different drugs prescribed appeared to be the strongest predictor of PIM use. Patients with a larger number of GOPC visits and more than six diagnoses were more likely to be exposed to PIM prescription. Hence, interventions such as medication review, evidence-based drug therapy recommendation guidelines for prescribers, and patient education should be strengthened on these vulnerable older adults.

To date, this is the first territory-wide study assessing the prevalence of PIM use in older adults visiting GOPCs, which represented over $40 \%$ of the ageing population in Hong Kong. Given the large sample size and the use of a relatively new version of the Beers criteria, the current results might be more precise than previous findings from Hong Kong. In addition, this study is one of the first attempts to identify the factors associated with PIM use in Hong Kong. Although the constant updating of the HA drug formulary has led to improvements in the quality of care, the present findings could help to enhance prescribing quality by quantifying the burden of PIM use in Hong Kong at the population level and identifying vulnerable patients who need further interventions. However, this study also has some limitations. First, the prevalence of PIM use may have been underestimated because of unaddressed PIMs related to indication, dose and therapy duration. Most of previous studies using administrative data sources have gaps in clinical information and drug exposure data. ${ }^{32}$ However, by contrast to the studies using medical records or surveys, the large administrative databases could offer information with representativeness, which yields more accurate estimates and power to detect statistical significance. These contributions allowed the use of administrative databases as a valid approach to assess the quality of healthcare. ${ }^{34}$ Second, the prevalence estimates of PIM use were only assessed in the context of the HA drug formulary. Patients may have other sources of PIMs such as private clinics or commercial pharmacies. Third, a new version of the Beers criteria was released in 2019 before the current study was conducted. ${ }^{16}$ In the 2019 updated Beers criteria, ${ }^{16}$ several drug-disease interactions from the 2015 AGS Beers criteria have been removed for not particularly problematic to older adults, while some new PIM statements have been added to the updated criteria. These changes were not considered in the current study. Therefore, the prevalence rates of PIM use in Hong Kong older patients need to be updated using the latest version of the Beers criteria in future studies. 
Furthermore, except for PIMs, inappropriate prescribing also includes potentially prescribing omissions, ${ }^{35}$ yet they are not evaluated in this study. Efforts should be made to narrow down this research gap in future studies.

The Beers criteria can be a useful tool to measure prescribing quality at the macro level so as to initiate action to prevent adverse drug events. ${ }^{14}$ However, it cannot replace prescribers' clinical judgement because the benefits of PIMs may outweigh risks at the individual level. Several researchers have found it difficult to adapt the Beers criteria to local situations because of contextual differences in terms of approved drugs, clinical practice and health system regulations. ${ }^{36} 37$ Therefore, several country-specific explicit criteria have been developed to assess the local prescribing quality. ${ }^{36-39}$ In 2019, a Hong Kong-specific PIM list was developed based on nine sets of published criteria and validated by a two-round modified Delphi process. ${ }^{40}$ Future studies should focus on comparing the ability of this Hong Kongspecific PIM list in assessing PIM use with the Beers criteria in older adults in Hong Kong.

\section{CONCLUSIONS}

In conclusion, the overall prevalence of PIM use in older adults visiting GOPCs in Hong Kong was high using the major subsets of the Beers criteria. Patients with female gender, a larger number of medications prescribed, more frequent visits to GOPCs, and more than six diagnoses were at higher risk for PIM use. Interventions should be strengthened on these vulnerable older adults, particularly in the context of older adults who are prescribed numerous medications.

Acknowledgements We would like to thank the Hong Kong Hospital Authority for providing us all the data that was required and coordination.

Contributors Study design: HZ, ELYW and EKY. Data analysis: HZ, FTTL and PYKC. Data interpretation: HZ, ELYW, SYSW, BHKY, RYNC and EKPL. Writing of the paper: $\mathrm{HZ}$ and ELYW. Revision of the paper: HZ, ELYW, SYSW, PYKC, BHKY, RYNC, EKPL,

FTTL and EKY. All authors have seen and approved the final version of the paper for publication.

Funding The work described in this paper was fully supported by a commissioned grant from the Health and Medical Research Fund (HMRF) of the Food and Health Bureau of the Government of the Hong Kong Special Administrative Region. (Project Code: Elderly Care - CUHK).

Competing interests None declared.

Patient consent for publication Not required.

Ethics approval The project has been granted ethical approval by the Survey and Behavioural Research Ethics Committee of the Chinese University of Hong Kong (Ref No: SBRE-19-433).

Provenance and peer review Not commissioned; externally peer reviewed.

Data availability statement All data relevant to the study are included in the article or uploaded as online supplemental information. No additional data are available.

Supplemental material This content has been supplied by the author(s). It has not been vetted by BMJ Publishing Group Limited (BMJ) and may not have been peer-reviewed. Any opinions or recommendations discussed are solely those of the author(s) and are not endorsed by BMJ. BMJ disclaims all liability and responsibility arising from any reliance placed on the content. Where the content includes any translated material, BMJ does not warrant the accuracy and reliability of the translations (including but not limited to local regulations, clinical guidelines, terminology, drug names and drug dosages), and is not responsible for any error and/or omissions arising from translation and adaptation or otherwise.

Open access This is an open access article distributed in accordance with the Creative Commons Attribution Non Commercial (CC BY-NC 4.0) license, which permits others to distribute, remix, adapt, build upon this work non-commercially, and license their derivative works on different terms, provided the original work is properly cited, appropriate credit is given, any changes made indicated, and the use is non-commercial. See: http://creativecommons.org/licenses/by-nc/4.0/.

\section{ORCID iDs}

Huanyu Zhang http://orcid.org/0000-0001-6480-2510

Roger YN Chung http://orcid.org/0000-0003-4407-8208

Francisco TT Lai http://orcid.org/0000-0002-9121-1959

\section{REFERENCES}

1 Motter FR, Fritzen JS, Hilmer SN, et al. Potentially inappropriate medication in the elderly: a systematic review of validated explicit criteria. Eur J Clin Pharmacol 2018;74:679-700.

2 Poudel A, Peel NM, Nissen L, et al. Potentially inappropriate prescribing in older patients discharged from acute care hospitals to residential aged care facilities. Ann Pharmacother 2014;48:1425-33.

3 Urfer M, Elzi L, Dell-Kuster S, et al. Intervention to improve appropriate prescribing and reduce polypharmacy in elderly patients admitted to an internal medicine unit. PLoS One 2016;11:e0166359.

4 Census and Statistics Department. Population Projections. [Internet] 2017. Available: https://www.censtatd.gov.hk/hkstat/sub/sp190.jsp? productCode=B1120015 [Accessed 17 Jun 2019].

5 United Nations. World population prospects 2019, 2019. Available: https://population.un.org/wpp/ [Accessed 09 Jan 2020].

6 Spinewine A, Schmader KE, Barber N, et al. Appropriate prescribing in elderly people: how well can it be measured and optimised? Lancet 2007;370:173-84.

7 Chang C-B, Yang S-Y, Lai H-Y, et al. Using published criteria to develop a list of potentially inappropriate medications for elderly patients in Taiwan. Pharmacoepidemiol Drug Saf 2012;21:1269-79.

8 Dimitrow MS, Airaksinen MSA, Kivelä S-L, et al. Comparison of prescribing criteria to evaluate the appropriateness of drug treatment in individuals aged 65 and older: a systematic review. J Am Geriatr Soc 2011;59:1521-30.

9 Beers MH, Ouslander JG, Rollingher I, et al. Explicit criteria for determining inappropriate medication use in nursing home residents. UCLA division of geriatric medicine. Arch Intern Med 1991;151:1825-32.

10 Beers MH. Explicit criteria for determining potentially inappropriate medication use by the elderly. An update. Arch Intern Med 1997;157:1531-6.

11 Fick DM, Cooper JW, Wade WE, et al. Updating the beers criteria for potentially inappropriate medication use in older adults. Arch Intern Med 2003;163:2716.

12 Jirón M, Pate V, Hanson LC, et al. Trends in prevalence and determinants of potentially inappropriate prescribing in the United States: 2007 to 2012. J Am Geriatr Soc 2016;64:788-97.

13 Chang C-B, Chen J-H, Wen C-J, et al. Potentially inappropriate medications in geriatric outpatients with polypharmacy: application of six sets of published explicit criteria. Br J Clin Pharmacol 2011;72:482-9.

14 American Geriatrics Society 2012 Beers Criteria Update Expert Panel. American geriatrics Society updated beers criteria for potentially inappropriate medication use in older adults. J Am Geriatr Soc 2012;60:616-31.

15 By the American Geriatrics Society 2015 Beers Criteria Update Expert Panel. American geriatrics Society 2015 updated beers criteria for potentially inappropriate medication use in older adults. $J$ Am Geriatr Soc 2015;63:2227-46.

16 By the 2019 American Geriatrics Society Beers Criteria ${ }^{\circledR}$ Update Expert Panel. American geriatrics Society 2019 updated AGS beers Criteria ${ }^{\circledR}$ for potentially inappropriate medication use in older adults. J Am Geriatr Soc 2019;67:674-94.

17 Opondo D, Eslami S, Visscher S, et al. Inappropriateness of medication prescriptions to elderly patients in the primary care setting: a systematic review. PLoS One 2012;7:1-10.

18 Jokanovic N, Tan ECK, Dooley MJ, et al. Prevalence and factors associated with polypharmacy in long-term care facilities: a systematic review. J Am Med Dir Assoc 2015;16:535.e1-535.e12.

19 Morin L, Laroche M-L, Texier G, et al. Prevalence of potentially inappropriate medication use in older adults living in nursing homes: a systematic review. J Am Med Dir Assoc 2016;17:862.e1-862.e9. 
20 Storms H, Marquet K, Aertgeerts B, et al. Prevalence of inappropriate medication use in residential long-term care facilities for the elderly: a systematic review. Eur J Gen Pract 2017;23:69-77.

21 Hospital Authority. Clusters, Hospitals \& Institutions. [Internet], 2019. Available: https://www.ha.org.hk/visitor/ha_visitor_index.asp? Content $I D=10036 \&$ Lang=ENG\&Dimension $=1 \&$ Ver $=$ HTML [Accessed 29 Jun 2019].

22 Hospital Authority. HA Strategic Plan. [Internet], 2019. Available: http://www.ha.org.hk/visitor/ha_visitor_text_index.asp?Content_ID= 224125\&Lang=ENG [Accessed 06 Dec 2019].

23 Lam DPY, Mak CF, Chan SMC, et al. Polypharmacy and inappropriate prescribing in elderly Hong Kong Chinese patients. J Am Geriatr Soc 2010;58:203-5.

24 Lam MPS, Cheung BMY, Wong ICK. Prevalence of potentially inappropriate prescribing among Hong Kong older adults: a comparison of the beers 2003, beers 2012, and screening tool of older person's prescriptions and screening tool to alert doctors to right treatment criteria. J Am Geriatr Soc 2015;63:1471-2.

25 HA Drug Formulary. Updated HA Drug Formulary. [Internet], 2018. Available: https://www.ha.org.hk/hadf/en-us/Updated-HA-DrugFormulary [Accessed 19 Apr 2018].

26 Thomas RE, Thomas BC. A systematic review of studies of the STOPP/START 2015 and American geriatric Society beers 2015 criteria in patients $\geq 65$ years. Curr Aging Sci 2019;12:121-54

$27 \mathrm{Kim}$ J, Parish AL. Polypharmacy and medication management in older adults. Nurs Clin North Am 2017:52:457-68.

28 Hospital Authority. Leaflets about GOPC services, 2019. Available: https://www.ha.org.hk/visitor/ha_visitor_index.asp?Parent_ID= 10052\&Content_ID=212848\&Lang=ENG\&Dimension=100 [Accessed $09 \mathrm{Jul}$ 2019].

29 Liu S, Yam CHK, Huang OHY, et al. Willingness to pay for private primary care services in Hong Kong: are elderly ready to move from the public sector? Health Policy Plan 2013;28:717-29.

30 Hospital Authority. Fees and charges, 2019. Available: https://www. ha.org.hk/visitor/ha_visitor_index.asp?Parent_ID $=10044 \&$ Content ID=10045\&Ver=HTML [Accessed 03 Jul 2019].
31 Wong SYS, Kung K, Griffiths SM, et al. Comparison of primary care experiences among adults in general outpatient clinics and private general practice clinics in Hong Kong. BMC Public Health 2010;10:397.

32 Guaraldo L, Cano FG, Damasceno GS, et al. Inappropriate medication use among the elderly: a systematic review of administrative databases. BMC Geriatr 2011:11:79.

33 Reich O, Rosemann T, Rapold R, et al. Potentially inappropriate medication use in older patients in Swiss managed care plans: prevalence, determinants and association with hospitalization. PLOS One 2014;9:23-5.

34 Wray NP, Ashton CM, Kuykendall DH, et al. Using administrative databases to evaluate the quality of medical care: a conceptual framework. Soc Sci Med 1995;40:1707-15

35 Medicine G, Medicine G, Ireland N. STOPP / start criteria for potentially inappropriate prescribing in older people: version 2 , 2015: 213-8.

36 Holt S, Schmiedl S, Thürmann PA. Potentially inappropriate medications in the elderly: the PRISCUS list. Dtsch Arztebl Int 2010;107:543-U39.

37 Laroche M-L, Charmes J-P, Merle L. Potentially inappropriate medications in the elderly: a French consensus panel list. Eur J Clin Pharmacol 2007;63:725-31.

38 Winit-Watjana W, Sakulrat P, Kespichayawattana J. Criteria for high-risk medication use in Thai older patients. Arch Gerontol Geriatr 2008;47:35-51.

39 Rognstad S, Brekke M, Fetveit A, et al. The Norwegian general practice (NORGEP) criteria for assessing potentially inappropriate prescriptions to elderly patients. A modified Delphi study. Scand J Prim Health Care 2009;27:153-9.

40 Zhang H, Wong EL, Yeoh E-K, et al. Development of an explicit tool assessing potentially inappropriate medication use in Hong Kong elder patients. BMC Geriatr 2021;21:98. 